\title{
Reproduksi Bahasa Krama Inggil melalui Kursus Pambiwara di Keraton Surakarta (Studi Kasus tentang Strategi Keraton Surakarta dalam Upaya Mempertahankan Legitimasi Kekuasaan Atas Kebudayaan Jawa)
}

\author{
Panggio Restu Wilujeng ${ }^{1} \&$ Hanneman Samuel ${ }^{2}$ \\ Sosiologi, Fakultas Ilmu Sosial dan Ilmu Politik Universitas Bangka Belitung \\ Sosiologi, Fakultas Ilmu Sosial dan Ilmu Politik, Universitas Indonesia, Depok 16424 \\ Indonesia \\ panggiorestu@gmail.com
}

\begin{abstract}
This study aims to investigate Krama Inggil language reproduction through courses of pambiwara keraton surakarta, as an effort by keraton to maintain power legitimacy on javanese culture, in relation to keraton's function that has been shifted into culture functionary. It is a qualitative study, a case study specifically. The theory used in this study is a theory by Pierre Bourdieu, which explains language as a symbolic power related to agent's survival strategy in the arena by utilizing possessed capital. This study shows that keraton has established a course of pambiwara as a strategy to reproduce cultural symbols that it has, particularly the use of Krama Inggil language to maintain keraton's power legitimacy on javanese culture as the oldest heritage of Mataram monarchy.
\end{abstract}

Keywords : Krama Inggil Language, Keraton Surakarta, Cultural Legitimacy, Reproduction, and Strategy

\section{ABSTRAK}

Tujuan penelitian ini untuk mengetahui reproduksi Bahasa Krama Inggil melalui Kursus Pambiwara Keraton Surakarta dalam upaya Keraton mempertahankan legitimasi kekuasaan atas kebudayaan Jawa berkaitan dengan fungsi Kraton yang beralih sebagai pemangku adat.Penelitianini menggunakan jenis penelitian kualitatif yaitu studi kasus.Teori yang digunakan adalah Teori Pierre Bourdieu yang menjelaskan bahasasebagai kuasa simbolik terkait dengan strategi bertahan agen di dalam arena dengan memanfaatkan modal (sosial, kultural, ekonomi, simbolik) yang dimiliki. Hasil penelitian menunjukkan, Keraton mendirikan Kursus Pambiwara.sebagai strategi untuk mereproduksi kembali simbol-simbol kebudayaan yang mereka miliki, terutama penggunaan Bahasa Krama Inggil untuk dapat mempertahankan legitimasi Keraton atas kebudayaan Jawa sebagai warisan tertua Kerajaan Mataram.

Kata Kunci : Bahasa Krama Inggil, Keraton Surakarta, Legitimasi Kebudayaan, Reproduksi, dan Strategi 


\section{PENDAHULUAN}

Masuknya modernisasi di kota Solo, membawa perubahan pada Masyarakat Solo yang tadinya memiliki struktur hirearkis dibawah Kraton, menjadi masyarakat yang lebih modernis,. Perubahan sosial yang terjadi mengubah struktur, khususnya stratifikasi masyarakat Solo yang dulunya feodal dan hierarkis menjadi lebih terbuka, egaliter dan demokratis. Perubahan gelombang tersebut terjadi karena modernisasi yang mentransformasikan orientasi masyarakat Jawa tidak lagi pada tradisi,ritual dan etiket budaya Jawa, melainkan orientasi pada kehidupan yang lebih modern (Soemardjan, 2009; Mulder, 2005).

Salah satu simbol masyarakat Jawa yang hierarkis adalah penggunaan ragam bahasa Krama Inggil. Bahasa ini dikonstruksi oleh Kraton untuk menunjukkan kekuasaan kerajaan terhadap masyarakat yang dikuasai. Namun, kini struktur masyarakat Solo sudah berubah dengan pemerintahan kota yang lebih administratif dan modern sedangkan Kraton sudah tidak lagi memiliki kekuasaan politik. Sehingga bahasa ini mengalami keterancaman dalam penggunaannya.

Salah satu fenomena yang muncul dalam upaya mempertahankan Bahasa Krama Inggil ini adalah munculnya Kursus Pambiwara.Kursus Pambiwara Sasana Marcukunda didirikan oleh Kraton untuk melayani orang-orang yang ingin belajar bahasa Krama Inggil secara lebih rinci dalam waktu singkat. Proses pembelajaran Bahasa Krama Inggil yang diajarkan di kursus ini berbeda dengan Krama Inggil yang diajarkan di sekolah formal di luar Kraton. Bahasa Krama Inggil ini langsung dari Kraton dengan segala intonasi dan penerapannya lewat tutur kata karena pada umumnya bahasa ini digunakan untuk orang-orang yang belajar berpidato dengan bahasa Jawa Krama Inggil untuk keperluankeperluan tertentu.

Dari permasalahan inilah penulis ingin melihat upaya Kraton Surakarta untuk mempertahankan dan melestarikan bahasa
Krama Inggil yang merepresentasikan kekuasaan mereka pada zaman dahulu di tengah kondisi masyarakat yang terus berubah ke arah yang lebih modern serta situasi Kraton yang mulai kehilangan citranya. Kraton selain kehilangan kekuasaan secara politik, juga belum lama ini kembali mengalami pergolakan, ketika terjadi perebutan tahta Raja selama 8 tahun. Sehingga Kursus ini bisa menjadi salah satu strategi yang dapat terus memperkuat legitimasi Kraton dalam sumber-sumber kebudayaan Jawa dan identitas Jawa yang melekat pada masyarakat Solo (Surakarta).Dari penelitian-penelitan dan studi sebelumnya, penulis belum menemukan kajian yang membahas tentang bahasa Krama Inggil dan upaya reproduksinya ini secara sosiologis.Penulis berharap bisa mengisi kekosongan kajian tersebut dengan penelitian ini.

\section{LANDASAN TEORI}

\section{Sosiologi Pierre Bourdieu}

1. Habitus adalah produk kinerja yang dihasilkan dalam tatanan produk sejarah kolektif, struktur objektif (seperti bahasa, ekonomi, dan lainlainnya) untuk mensukseskan reproduksi mereka dalam bentuk sistem disposisi yang tahan lama... (Bourdieu 1977:82-85 ). Habitus merupakan rangkaian yang dialektis antara struktur internal dan eksternal agen berdasarkan pengalaman dan sejarah agen dalam menjalani kehidupannya di dunia sosial. Ini menjadi penekanan Bourdieu untuk keluar dari pilihan antara subyektivisme dan obyektivisme, dimana agen berpengaruh terhadap praktik dunia sosial, begitu pula dunia sosial berpengaruh juga terhadap praktik agen. Habitus memberikan ruang bagi seseorang untuk bertindak sesuai akal sehat (common sense) nya untuk 
membangun cara atau tindakan hidupnya (way of life) dengan berbagai strategi di tengah kehidupan sosial.

2. Capital atau modal, berhubungan dengan kapasitas untuk menggunakan kontrol diatas seuatu yang akan dimiliki sendiri atau pada orang lain. Bourdieu fokus pada interplay antara 4 jenis modal yaitu, modal sosial, kultural ekonomi dan simbolik. Modal ekonomi adalah modal ekonomi dalam pengertian umum dengan bentuk yang paling efisisen, dimana modal simbolik dapat menyembunyikan dominasi ekonomi dan dominasi kelas serta hierarki sosial yang terlegitimasi. Modal kultural adalah modal yang terdiri dari pengetahuan dan legitimasi, modal sosial terdiri dari hubungan sosial bernilai antar orang, dan modal simbolis tumbuh dari harga diri dan prestise (Ritzer \& Goodman 2009:583) Modal-modal itulah yang nantinya akan digunakan agen di dalam arena, yang digambarkan Bourdieu seperti pasar yang kompetitif atau seperti arena pertempuran. Agen menggunakan strategi dan modal yang mereka miliki untuk meraih atau mempertahankan posisi mereka di dalam arena.

3. Field atau Arena, adalah tempat dimana terjadinya kompetisi, perjuangan atau pertarungan dari orang-orang untuk memperoleh posisi atau kedudukan, mengamankan atau meningkatkan posisi mereka dalam struktur, dimana modal sosial, kultural, ekonomi dan simbolik digunakan dalam mereka melakukan strategi. (Ritzer \& Goodman, 2009:583-54). Dalam bukunya Distinction (1984) Bourdieu merumuskan formula bagaimana hubungan antara habitus yang didukung oleh modal (capital) jika diterapkan ke arena akan menghasilkan praktik yang diproduksi dan direproduksi dalam dunia sosial (Bourdieu, 1984:101) .

4. Bahasa merupakan salah satu bentuk dari bentuk-bentuk simbolik. Namun bahasa menjadi bentuk simbolik yang paling khas karena bahasa digunakan dimanapun manusia berada. Bahasa juga merupakan bentuk simbolik yang paling formal, karena bagaimanapun bahasa tetap memiliki makna tanpa harus terwujud dalam simbol-simbol nyata.Bahasa juga membentuk sekaligus dibentuk oleh realitas sosial. Semua orang, individu, atau agen dapat menggunakan bahasa secara bebas. Dengan kata lain bahasa merupakan simbol mendasar yang bisa digunakan setiap orang dimana setiap orang dapat memproduksi dan mereproduksi bahasa tersebut. Dalam konsep Bourdieu mengenai kapital, bahasa dikategorikan sebagai Symbolic Capital, atau modal simbolik. Modal simbolik inilah yang nantinya dipertarungkan ke dalam Field atau arena, bersama-sama dengan modal sosial, ekonomi dan modal kultural yang bisa saling dipertukarkan. Modal simbolik muncul dari harga diri atau prestise seseorang yang bisa digunakan sebagai pembentukan image dirinya di ranah sosial, yang dapat menjadi strategi nya ketika bertarung di tengah arena termasuk melalui bahasa.

Teori tersebut ingin penulis aplikasikan dalam mellihat fenomena Kursus Pambayawara Sasana Marcukunda di Surakarta, dimana bahasa Krama Inggil direproduksi sebagai upaya Kraton untuk mengembalikan dan mepertahankan legitimasinya dalam kebudayaan Jawa. Bahasa Krama Inggil kini berada di tengahtengah banyak masuknya ragam bahasa seperti Bahasa Indonesia, Bahasa Inggris 
dan kentalnya Bahasa Jawa Ngoko sebagai bahasa Jawa yang asli milik pribumi. Penulis melihat keberadaan kursus ini adalah upaya dalam menyebarkan dan mereproduksi bahasa Krama Inggil yang diklaim sebagai kebudayaan asli dari kerajaan mataram ditengah mulainya dipakai bahasa-bahasa lain karena perkembangan modernisasi kota Solo itu sendiri, ditambah dengan kekuasaan Kraton Kasunanan Surakarta yang tidak begitu kuat seperti di Yogyakarta.

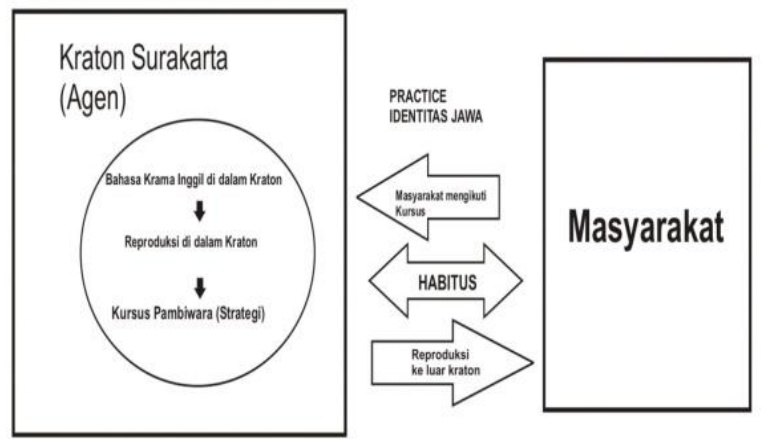

\section{III.METODE PENELITIAN}

Jenis Penelitian ini adalah penelitian dengan metode penelitian kualitatif menggunakan strategi studi kasus. Sebagaimana dijelaskan dalam Creswell (2016:19) "Stake (1995) Studi kasus, dimana peneliti menjelajah secara mendalam terhadap suatu program aktifitas, proses satu atau lebih individu/Kasus terikat oleh waktu dan aktifitas .dan peneliti mengumpulkan informasi secara mendetai dengan menggunakan variasi prosedur pengumpulan data dalam periode waktu tertentu". Penelitian ini dilakukan di di dalam Sanggar Pasinaon Pambiwara berada dibawah Yayasan Pawiyatan Kabudayan Kraton Kasunanan Surakarta Teknik pengumpulan data dalam penelitian ini adalah, observasi di dalam kegiatan Kursus Pambiwara tersebut, kemudian wawancara mendalam untuk mengetahuikedalaman informasi mengenai keberadaan, fungsi dan tujuan Kursus Pambiwara ini Selanjutnya, peneliti juga mengumpulkan data dari dokumendokumen, terkait dengan penelitian seperti sejarah dan perkembangan Bahasa Jawa Krama Inggil sampai pada masa sekarang ini serta materi-materi yang diajarkan di dalam Kursus.

\section{IV.HASIL PENELITIAN DAN PEMBAHASAN}

\section{A. Hasil Penelitian}

\section{Kursus Pambiwara}

Sanggar Pasinaon Pambiwara, Pawiyatan Pambiwara atau sering disebut Kursus Pambiwara adalah salah satu kegiatan kebudayaan yang ada di dalam Kraton Surakarta dibawah Yayasan Pawiyatan Kabudayan Kraton Surakarta Hadiningrat. Kursus ini didirikan pada tahun 1993 atas dasar perintah Raja Sunan Pakubuwana XII kepada humas Kraton Kanjeng Raden Mas Haryo Yosodipuro untuk mencari teman dan mendirikan semacam sanggar yang mengemban pelestarian kebudayaan terutama bahasa Jawa.Hal tersebut diinginkan oleh Raja karena Sunan merasa bahwa masyarakat Jawa saat ini tidak lagi bisa berbahasa Jawa dengan baik, tidak berbudaya Jawa dan tidak lagi mahir dalam menulis aksara Jawa. Bagi Sunan, bahasa Jawa dan budaya Jawa merupakan sumber dari pembentukanKursus ini berada di bawah Yayasan Pawiyatan Kabudayan Kraton Surakarta. Yayasan Pawiyatan ini diketuai oleh Gusti Raden Ayu Koes Moertiyah Wandasari (Gusti Mung), putri dari Sunan Pakubuwana 12. Kursus ini dipimpin oleh Kanjeng Pangeran Haryo Raditya Lintang Sasongko, M.Si (Bambang Irawan),

Kursus ini berkembang seiring berjalannya waktu. $\mathrm{Di}$ tengah perjalanannya, di tahun 1998 hingga tahun 2000an jumlah peserta mencapai 200 lebih siswa. Karena pada waktu itu keberadaan kursus ini sering diumumkan melalui Radio Republik Indonesia (RRI) Kota Surakarta, dan informasi juga menyebar dengan cepatnya dari mulut ke mulut (gatuk tular). Karena tidak ada syarat khusus dalam mengikuti Kursus 
ini, peserta menjadi banyak yang mendaftar dan mengikuti Kursus ini. Peserta yang membludak membuat Kraton kewalahan dalam mempersiapkan kegiatan.

Pekerjaan sebagai pengurus dan pengajar di dalam Kursus ini memang menjadi bagian pekerjaan dari abdi dalem Kraton untuk mematuhi dan mengabdi pada titah Raja-raja sebelumnya dengan oriaentasi pengabdian seumur hidup, Jadi berapapun biaya yang dikeluarkan dan sesulit apapun pekerjaan yang dilakukan, mereka tetap menjalankannya dengan sukarelatanpa mengharapkan imbalan apapun dari Kraton.

2. Tujuan didirikan Kursus

Tujuan dari didirikannya Kursus Pambiwara ini bagi Kraton adalah untuk nguri-uri budaya Jawa, yang artinya melestarikan kebudayaan Jawa. Posisi Kraton saat ini sudah tidak memiliki kekuasaan politik lagi semenjak bergabung ke NKRI dan fungsi Kraton Surakarta saat ini adalah sebagai Pusat Kebudayaan Jawa.Kursus Pambiwara merupakan salah satu elemen kebudayaan Kraton yang sangat penting bagi Kraton dalam pengembangannya, karena di dalamnya ada ragam Krama Inggil yang diajarkan. Krama Inggil bagi Kraton bukan hanya sekedar bahasa, namun bahasa ini bisa menunjukkan sikap penghormatan terhadap orang lain, sikap halus dan perilaku yang lembut yang merepresentasikan kebudayaan Jawa. pengurus di dalam Kraton, meyakini bahwa kebudayaan yang mereka miliki ini akan terus bertahan dan tidak akan pernah hilang. Masyarakat pun mereka yakini akan melihat Kraton sebagai pusatnya kebudayaan Jawa.Sehingga bagi mereka Kraton sampai kapan pun akan bertahan dengan budayanya.

3. Pengembalian dan Pelestarian Legitimasi Kraton Atas Budaya
Kraton mendirikan Kursus ini tidak untuk menimbulkan kesan bahwa Kraton membutuhkan masyarakat untuk mempelajari kebudayaan Jawa, Kraton tidak ingin dilihat sebagai penjual budaya Jawa, tetapi Kraton disini menganggap kegiatan ini sebagai bentuk pelestarian budaya Jawa dengan Kraton itu sendiri sebagai umber budaya tersebut. Sehingga Kraton menganggap dirinya sebagai pusat referensi kebudayaan Jawa peninggalan Kerajaan Mataram yang paling tua.Tujuan Kraton dalam mengembangkan budaya ini sudah tercapai bagi mereka, karena penyebaran Kursus yang cukup luas hinggake luar Kraton melalui tangan para alumni siswa dan para pengajarnya. Hal ini menjadi kebanggaan Kraton karena melihat tiap semesternya, Kraton selalu didatangi siswa- siswa baru yang ingin belajar di kursus ini. Kraton juga menganggap bahwa mereka juga sangat diakuiposisinya oleh pemerintah.

Kraton memiliki pakem-pakem bahasa Krama yang berbeda dari bahasa Krama yang ada di luar. Sehingga ketika siswa belajar di dalam Pawiyatan, kekeliruan-kekeliruan siswa dalam menggunakan bahasa tersebut akan diluruskan dan disesuaikan dengan standard bahasa Kraton. Kursus inimemang untuk membedakan bahasa dalam Kraton dengan bahasa-bahasa di luar Kraton, yang dianggap Kraton sebagai bahasa pengembangan. Hal ini juga untuk menegaskan bahwa budaya Kraton adalah budaya yang menjadi warisan tertua dari Kerajaan Mataram. Kraton memiliki pakem-pakem bahasa Krama yang berbeda dari bahasa Krama yang ada di luar.

Kraton memegang memegang prinsip yang ditanamkan kepada para siswanya " aja mrawesa budaya mengko mundak sulaya" yang artinya jangan memaksakan kebudayaan nanti menjadi bermasalah. Kraton memanggap setiap masyarakat memiliki kebudayaan 
sendiri-sendiri. Mereka tidak menyalahkan ketika orang-orang menggunakan bahasa tidak sesuai dengan standar Kraton. Hal tersebut menunjukkan bahwa Kraton tidak terlalu militan dalam menyebarkan kebudayaannya, mereka menanamkan kepada siswa untuk tidak memaksakan kebudayaannya orang lain. Kraton melestarikan kebudayaannya dengan cara melayani siapa yang ingin mempelajari budaya mereka. Kursus ini juga tidak menginformasikan kegiatan ini dengan menggunakan media promosiap apaun, karena Kraton tidakingi menimbulkan kesan bahwa Kraton yang membutuhkan Masyarakat untuk mempertahankan budayanya. Tetapi jika ada masyarakat yang tertarik untuk belajar di Kraton, akan dilayani.

Kursus Pambiwara menjadi ujung tombak bagi Kraton dalam pelestarian kebudayaannya karena bisa langsung diakses oleh masyarakat yang ingin mempelajarinya. Kebudayaan tersebut juga bisa ditanamkan ke dalam diri orang-orang yang belajar di dalamnya. Dalam kursus ini juga banyak bentuk sikap kesukarelaan dalam menjaga dan mempertahankan kebudayaan Jawa khususnya bahasa Krama Inggil ini agar tetap hidup di Kraton.

Di dalam kursus habitus yang selaras dibangun di melalui proses pemberian materi. Kraton memiliki legitimasi pengetahuan dalam penyebaran bahasa sekaligus kebudayaan yang dimiliki oleh Kraton.Nilai-nilai Jawa yang ada di Kraton Surakarta ditanamkan kepada siswa-siswa yang belajar di kursus tersebut, agar dapat mempertahankan bahasa ini dan melestarikannya ketika sudah lulus dari pawiyatan ini.Kraton berharap siswa-siswa yang mereka luluskan bisa konsisten dan membuat orang bisa tetarik untuk belajar di Kraton. Kraton juga meyakini bahwa masyarakat Jawa pasti akan banyak yang ingin mempelajari tentang budaya dan bahasa Jawa di Kraton. Hal yang dibangun oleh Kraton adalah wejangan kepada siswa-siswanya untuk berperilaku sesuai adat atau tradisi yang telah diajarkan di dalam Kraton.

Kursus ini memiliki tempat tersendiri di dalam Kraton, dimana permasalahan apapun yang terjadi, kursus harus tetap berjalan. Seperti konflikinternal yang terjadi dalam tubuh Kraton, tidak memberikan dampak yang serius bagi pengembangan Kursusini.Kursus ini tetap berjalan sebagaimana mestinya.Ini ditekankan oleh para abdi dalem karena Kursus ini menjadi tanggung jawab mereka atas dasar pengabdian kepada sabda Raja Pakubuwana XII yang mentitahkan tugas untuk melestarikan kebudayaan Jawa terutama melalui bahasa.

\section{B. Pembahasan}

Modernisiasi membawa perubahan signiffikan dalam kehidupan sosial masyarakat Solo. Kehidupan tradisional Masyarakat Solo yang tercermin oleh Kraton, luntur bersamaan dengan pudarnya kekuasaan Kraton secara politik setelah bergabung dengan NKRI di era pemerintahan Paku Buwana XII. Untuk itu Kraton tetap bertahan di Arena Kebudayaan dimana Kraton memiliki dan menguasai sumber-sumber kebudayaan Jawa.

Berbagai upaya telah dilakukan oleh PB XII pada masa pemerintahannya untuk menjadikan Kraton sebagai cagar budaya yang melestarikan kebudayaan Jawa warisan kerajaan mataram Islam. Salah satu upaya yang dilakukannya adalah dengan mendirikan Pawiyatan Pambiwara dibawah Yayasan Pawiyatan Kabudayan Kraton Surakarta yang dibuka untuk masyarakat umumDi dalam Kursus mengajarkan kebudayaan-kebudayaan Jawa, terutama simbol yang paling central dalam pengembangan kebudayaan Jawa, yaitu Bahasa Krama Inggil. 
Bahasa Krama Inggil yang dulunya digunakan untuk menghormati orang yang posisinya lebih tinggi. Bahasa Krama Inggil digunakan untuk membedakan kelas. Namun saat ini, bagi Kraton, bahasa ini kini beralih fungsi menjadi bahasa untuk menunjukkan sikap menghargai dan menghormati orang lain. Kursus ini merupakan strategi Kraton untuk dapat mereproduksi Bahasa Krama Inggil yang menjadi simbol utama dalam identitas Jawa yang dibawa oleh Kraton Surakarta untuk dapat dipelajari oleh masyarakat luas.

Di dalam kursus ini kebudayaan Kraton dan bahasa Krama Inggil sebagai unsur utama kebudayaan Jawa diajarkan atau disosialiasikan kepada masyarakat agar masyarakat mengenalnya dan dapat melestarikannya. Kebudayaan Kraton yang disosialisasikan atau coba direproduksi selain bahasa ada bermacam-macam dari mulai sejarah, simbol-simbol budaya, tradisi, busana, tingkah laku seseuai adab Kraton,tarian, macapat (menyanyikan tembang) dan lain-lain. Strategi ini bisa digunakan oleh Kraton untuk mengembalikan legitimasi kekuasaannya melalui kebudayaan.

Bahasa Krama Inggil bagi Kraton bukan hanya sekedar bahasa. Bahasa Krama Inggil bagi Kraton menunjukkan sikap yang halus dan membentuk karakter seseorang yang dianggap santun dan penuh penghormatan. Jika bahasa ini mulai hilang dan tergantikan oleh bahasa-bahasa lain yang lebih modern, maka simbol-simbol penghormatan orang Jawa terhadap Kraton akan terkikis. Sehingga legitimasi kekuasaan Kraton atas budaya menjadi semakin menurun.

Ini merupakan Identitas Jawa dimana karakternya ingin ditunjukkan dan dibentuk Kraton melalui Kursus Pambiwara ini. Dalam hal ini, Kraton berusaha mereproduksi terus menerus kebudayaannya, terutama bahasa, melalui kursus ini agar tidak hilang karena di dalam Kraton sendiri bahasa ini kurang berkembang.
Bahasa ini terus menerus muncul dan menarik minat masyarakat Solo itu sendiri untuk memakainya dan bahasa Krama Inggil terus berkontestasi di tengah era modern ini. Kursus ini menjadi strategi Kraton dalam mengembalikan legitimasi kekuasaan atas budaya, karena yang direproduksi di sini bukan hanya bahasa Krama Inggil yang memiliki nilai budaya tinggi, tetapi juga simbol-simbol kebudayaan Kraton yang memiliki nilai tinggi bagi Masyarakat Solo. Upaya Kraton Surakarta dalam mengembalikan legitimasi kebudayaan ini, adalah upaya pengembalian kebudayaan tradisional yang terus digempur oleh modernitas dan budaya massa, dengan cara menghegemoni masyarakat bahwa budaya Jawa yang berasal dari Kraton ini adalah budaya yang tinggi. Kursus memainkan semua modal yang dimiliki untuk dapat memunculkan modal kultural berupa bahasa dan tradisi-tradisi kebudayaan Jawa milik Kraton ini untuk bisa keluar. Hal ini ditunjukkan dengan pengorbanan Kraton secara finansial dalam mengupayakan agar Kursus ini tetap berjalan. Pengorbanan juga dilakukan oleh para pengajar dan abdi dalem yang mau menyisihkan penghasilan mereka untuk keperluan akomodasi dalam mengajar.Siswa juga ditanamkan nilai-nilai budaya Kraton yang adiluhung untuk dicintai dan dilestarikan serta dikembangkan agar tidak punah. Dalam hal ini,modal kultural lebih dominan dibandingkan dengan modal-modal yang lain karena ini memang menjadi tujuan Kraton Surakarta sebagai strategi untuk bertahan di arena budaya.

Selain menjadi agen itu sendiri, Kraton juga menggunakan agen-agen yaitu masyarakat yang menjadi siswa di dalam Kursus Pambiwara. Upaya Kraton tidak hanya melalui Kursus, tetapi juga dengan bantuan pemerintah Kota Surakarta Kraton mengadakan pelatihan mengenai pelestarian budaya ini. Strategi Kraton untuk mereproduksi bahasa Krama Inggil dan identitas budaya Jawa tidak hanya berhenti di dalam Kraton atau menunggu siswa-siswa masuk setiap semesternya, namun siswa- 
siswa yang pernah belajar di dalam kursus ini juga membangun Kursus-kursus yang serupa di lingkungan mereka sehingga dapat memperluas reproduksi identitas Jawa Kraton Surakarta ini. Sehingga proses reproduksi ini lebih luas dan mencakup daerah-daerah yang jauh dari Kraton.

Kemunculan dan berkembangnya Kursus ini mereproduksi kelas yang baru berdasarkan selera atau bourdieu menyebutnya dengan distingsi. Selera dalam konteks penelitian ini adalah selera mengenai budaya. Hal tersebut ditunjukkan dengan adanya standardisasi Kraton dan kecintaan para siswa dan Dwija untuk melestarikan budaya ini karena dianggap lebih tinggi dari kebudayaan yang lain. Meskipun saat ini lebih dominan selera terhadap bahasa asing, tetapi jika menggunakan perspektif Bourdieu, kebudayaan dan identitas Jawa ini akan terus berkontestasi di arena Budaya dengan legitimasi Kraton yang masih memiliki posisi sebagai pemangku adat dan kebudayaan Jawa yang masih dianggap tinggi oleh masyarakat Surakarta itu sendiri. Kursus menanamkan habitus dalam bertingkah laku kepada siswa, untuk dapat diterapkan dalam kehidupan sehari-harinya ketika berbicara dengan orang lain. Jika melihat dengan pemikiran bourdieu mengenai habitus, artinya siswa-siswa dalam Kursus ini nantinya akan "mengeksternalisasikan struktur". Habitus tersebut dibentuk untuk menunjukkan simbol Kraton yang tertanam dalam diri siswa-siswa tersebut, yang kemudian dikembangkan keluar.

Kraton menjadi penopang dalam upaya mempertahankan kebudayaan Jawa, tidak hanya secara fisik dilihat sebagai cagar budaya, tetapi juga sumber daya kultural yang kaya akan kebudayaan Jawa. Jika kultur Jawa ini tidak dipertahankan dan lama kelamaan hilang, bisa berdampak pada kemunduran otoritas Kraton atas budaya dan juga legitimasi kekuasaannya sebagai pusat kebudayaan Jawa di Surakarta, bahkan seluruh nusantara. Keberadaan Kursus ini berdiri secara mandiri, tidak terpengaruh oleh segala polemik yang terjadi di dalam tubuh Kraton Kursus ini menjadi ujung tombak bagi Kraton dalam upaya mereproduksi bahasa Krama Inggil untuk melegitimasi kekuasaan. Kursus ini juga menjadi sarana dalam pengembangan kebudayaan Jawa asli Kraton Surakarta.

\section{KESIMPULAN}

Kemunduran Kraton dalam legitimasi kekuasaan dan konflik internal berdampak pada keterbatasan Kraton dalam mengelola sumber daya kulturalnya dan citranya di mata masyarakat.Pergolakan yang terjadi beriringan dengan berkembangnya Kota Solo menjadi Kota yang lebih modern. Upaya pelestarian budaya terus dilakukan oleh Kraton agar kebudayaan Jawa dengan segala tradisinya tidak hilang tergerus oleh modernisasi. Kraton merasa memiliki tanggung jawab moral untuk mempertahankan kebudayaan lokalnya.

Salah satu upaya yang dilakukannya adalah dengan mendirikan Pawiyatan Pambiwara dibawah Yayasan Pawiyatan Kabudayan Kraton Surakarta yang dibuka untuk masyarakat umum. Kursus ini memberikan materi-materi kebudayaan asli Kraton Surakarta dengan ragam bahasa Krama Inggil.

Hal yang menonjol dalam Kursus ini adalah pemakaian ragam bahasa Krama Inggilnya .Penekanannya pada bahasa Krama Inggil yang memiliki perbedaaan dengan bahasa Krama yang ada di luar Kraton. Kepada setiap siswa ditanamkan mengenai pemakaian bahasa Krama Inggil yang sesuai standar di Kraton yang memiliki karakter lembut dan penuh penghormatan dalam pengucapannya, Tak hanya itu, penggunaan bahasa ini juga menjadi unsur penting dalam setiap penyelenggaraan tradisi dan kebudayaan Jawa yang berasal dari Kraton.

Baik Kraton maupun masyarakat yang belajar di dalam Kursus memainkan semua modal yang dimiliki untuk dapat memunculkan modal kultural berupa bahasa 
dan tradisi-tradisi kebudayaan Jawa milik Kraton ini untuk bisa keluar. Upaya reproduksi bahasa sebagai representasi identitas Jawa menjadi titik paling menonjol dalam penyelenggaraan Kursus ini.Hal ini ditunjukkan dengan pengorbanan Kraton secara finansial dalam mengupayakan agar Kursus ini tetap berjalan. Namun hingga sejauh ini upaya pencapaian kekusaan secara politik tidak dapat dicapai oleh Keraton melalui bahasa dan bentuk-bentuk kebudayaannya yang lain. Keraton hanya dapat mempertahankan legitimasi kekuasaannya di dalam ranah atau arena kebudyaan. Hal ini menjadi kritik bagi pemikiran Bourdieu bahwa tidak semua modal bisa dikonvesikan menjadi modal atau ke dalam arena yang lain.

Kursus Pambiwara merupakan salah satu elemen kebudayaan Kraton yang sangat penting bagi Kraton dalam pengembangannya, karena di dalamnya ada ragam Krama Inggil yang diajarkan. Bahasa Krama Inggil juga penting bagi Kraton untuk diajarkan karena bahasa ini menjadi bahasa yang menunjukkan identitas Jawa yang sebenarnya, yang dinilai sebagai budaya yang tinggi (adiluhung). Para Dwija dan pengurus di dalam Kraton, meyakini bahwa kebudayaan yang mereka miliki ini akan terus bertahan dan tidak akan pernah hilang. Masyarakat pun mereka yakini akan melihat Kraton sebagai pusatnya kebudayaan Jawa. Sehingga bagi mereka Kraton sampai kapan pun akan bertahan dengan budayanya. Hal ini berkaitan dengan pengembalian legitimasi Kraton yang semakin memudar dengan terjadinya berbagai pergolakan dan semakin tumbuhnya Kota Solo menjadi Kota yang lebih modern. Kursus ini menjadi ujung tombak bagi Kraton untuk terus menmpertahankan legitimasi kekuasaannya sebagai pusat Kebudayaan di Surakarta. Kursus ini akan terus dikembangkan oleh Kraton agar tidak hilang dan terus berjalan sesuai dengan nut jaman kelakone (sepanjang zaman yang dilalui). Kraton Surakarta sebagai pemangku adat dan kebudayaan Jawa, dimana mereka juga merepresentasikan identitas Jawa itu sendiri akan terus berkontestasi dengan kebudayaan modern di tengah kehidupan modern untuk tetap dapat mempertahankan legitimasi kekuasaannya atas kebudayaan.

\section{DAFTAR PUSTKA}

[1] Bourdieu, Pierre. (1977). Outline of a Theory of Practice. Cambridge University Press, London.

[2] Bordieu, Pierre. (1984). Distinction : A Social Critique of the Judgment Taste. Mass: Havard University Press, Cambridge.

[3] Creswell, John W. (2016). Research Design Qualitative, Quantitative and Mixed Methods Approaches, 2nd. edn., Sage Publications, Inc

[4] Mulder, Niels. (2005). Inside Indonesian Society: Cultural Change in Java. Kanisius, Yogyakarta.

[5] Ritzer, George \& Goodman, Douglas J. (2009). Teori Sosiologi (terjemahan). Kreasi Wacana, Yogyakarta.

[6] Soemardjan, Selo. (2009). Perubahan Sosial di Yogyakarta. Komunitas Bambu, Jakarta. 